\title{
Software for recording observational files
}

\author{
ANTONIO HERNÁNDEZ MENDO \\ University of Málaga, Málaga, Spain \\ MARÍA TERESA ANGUERA ARGILAGA \\ University of Barcelona, Barcelona, Spain \\ and \\ MIGUEL ANGEL BERMÚDEZ RIVERA \\ University of A Coruña, A Coruña, Spain
}

\begin{abstract}
We offer the new software Codex, written in Visual Basic 3.0. It is a tool adequate in observational methodology. Its fundamental objective is to record motor and verbal behavior using the data types proposed by Bakeman and Quera $(1995,1996)$, together with the field formats proposed by Hall (1963), Weick (1968), Hutt and Hutt (1974), and Anguera (1979). It is designed to allow for data interchange between specific programs in use in observational methodology (SDIS-GSEQ, The Observer, and Theme) and other general programs (spread sheets, statistics applications, word processing programs, sound cards, etc.).
\end{abstract}

The Codex ${ }^{1}$ program is a computer application used for observing sportive situations. Its antecedent was the Transcriptor program, which was elaborated by our research group (Hernández Mendo, 1994; Hernández Mendo \& Ramos, 1996a, 1996b; Hernández Mendo, Ramos, Peralbo, \& Risso, 1993; Peralbo, Risso, Ramos, \& Hernández Mendo, 1992; Ramos, Hernández Mendo, Peralbo, \& Risso, 1994). The Transcriptor software was an especially useful tool for the coding and recording of physical activities. Therefore it is possible to merge recordings from concurrent behaviors and as well to save sequence behaviors.

The current program attempts to improve on the features of the old one. It offers a recording tool that makes it possible to record behavioral flow in any situation (either in situ observations or motor or verbal behavior recordings, on video- or audiotape). Codex uses the syntax proposed by Bakeman and Quera $(1995,1996)$ and also makes it possible to export data to the Sequential Data Interchange Standard (SDIS) program (Bakeman \& Quera, 1995). Moreover, data can be imported from files created with Transcriptor, which allows for analysis of verbal production gathered in observations and exports files into The $\mathrm{Ob}-$ server 3.0 (Noldus, 1991) and Theme (Magnusson, 1988, 1993) programs.

The program is written in Visual Basic, making it possible to work in a multitasking environment such as Windows, thus facilitating use of this software. Besides those proposed by Bakeman and Quera (1995), the options

Correspondence should be addressed to $\mathrm{A}$. Hernández Mendo, Departamento de Psicología Social y de la Personalidad, Facultad de Psicologia, Universidad de Málaga, Campus de Teatinos, S/N, 29071 Málaga, Spain (e-mail: mendo@uma.es). available in terms of the type of data include event sequential data (ESD), state sequential data (SQD), time event sequential data, and interval sequential data. Field formats include those proposed by Hall (1963), Weick (1968), Hutt and Hutt (1974), and Anguera (1979).

This software allows us to record nonverbal and verbal behavior. With reference to verbal production, the program makes it possible to calculate the number of letters involved in each verbal emission, the number of words, and the mean length of statements. It can also label a part or each one of the words or word groups according to the type of study being done or the theoretical model underlying the research project. It performs a study of the frequency of words based on the context in which they are found. The program generates an independent ASCII file for the text (or the analysis results of verbal production) that can be read by a word processor or a sound card, which reproduces the emission in the case of text.

\section{Functional Structure of the Program}

To write the program, a Visual Tools-type language was chosen, specifically Visual Basic 3.0, which solves user interface needs through a graphic mode and the ease of language in Windows, economizing on time used for screen creation and design.

In the design of this application, the programming environment was structured through the use of files and data interchange between screens. Files were organized sequentially and recorded in ASCII. File input and output were done line by line using "Print" and "Line Input" techniques. Files and handles were chosen automatically within the program. Outputs were filed with extensions referring to the type of data used (*.eve, *.est, *.int, *.mix, and *.fam for events, states, intervals, time events, and field formats, respectively). These files can be opened from any 


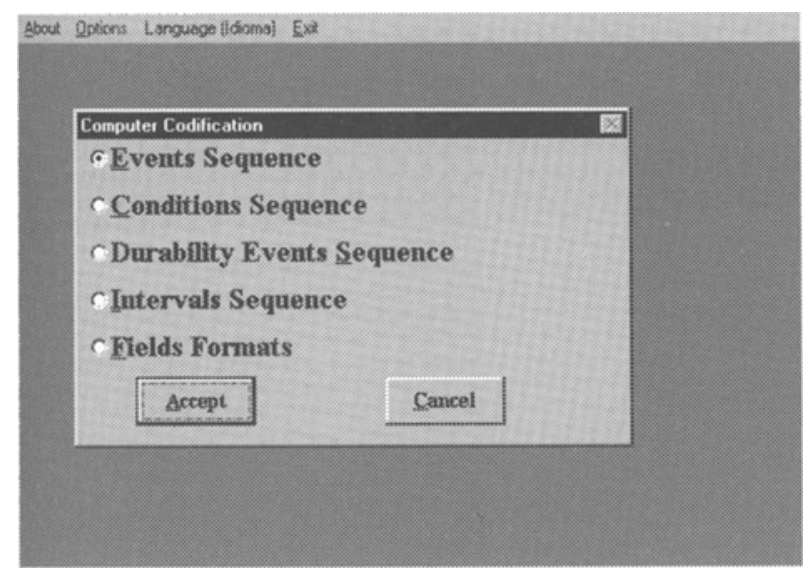

Figure 1. Beginning screen.

word processor that can read ASCII files, but the saving format must be adhered to for it to be recognized by the program.

Despite the fact that files generated by data type have different extensions, they have parts in common that make it possible to interchange different types of observation and/or data (subjects, codes, observations, etc.). The program therefore allows for direct connection with Bakeman and Quera's (1995, 1996) SDIS-GSEQ program, The Observer 3.0 (Noldus, 1991), Theme (Magnusson, 1988, 1993), SPSS-type statistics packages, and spread sheets, as well as data imported from Transcriptor (Hernández Mendo, 1994; Hernández Mendo \& Ramos, 1996a, 1996b; Hernández Mendo et al., 1993; Peralbo et al., 1992; Ramos et al., 1994).

Data interchange is necessary for program management and is based on placing information on lists (which can either be pull-down lists or not) for easy access. When a window is loaded, references are established with this list so that the information is always available from any other window by adding a reference prefix.

The use of the drag-drop technique makes it possible to eliminate entering code and/or subject entries. These entries are, however, stored in the memory so that, if an error is made, the user can go back and recover the data erased.

The program has a modular top-down structure that optimizes organization and flow control and makes it easy to pinpoint problems.

\section{Working Options}

The program was designed (Hernández Mendo, 1996) to be easy to use and applicable to any type of situation and any type of data. For this reason, the first screen the program automatically goes into is the first of the two possible types of observation ("Taped Recording" and "In Situ Recording"), although logically, we can always choose between the two. The options on this first screen are "About," "Options," "Exit," a pull-down menu on the left side of the screen, and an icon in the bottom left-hand corner. The "About" option shows the names of the authors. " "Options" shows the two types of situations in which the observation sessions can be carried out. The "In situ Recording" option also appears as an icon in the bottom left-hand corner of the screen. With the "Exit" option, the user can leave the program and go back to Windows.

The screen that appears when the program is opened (see Figure 1), which belongs to the "Taped Recording" option (this option can be changed either in the pulldown menu or by clicking the mouse on the icon in the bottom left-hand corner), shows the type of data that can be worked with: event sequential data ("Events Sequence"), state sequential data ("Conditions Sequence"), time event sequential data ("Durability Events Sequence"), interval sequential data ("Intervals Sequences"), and "Fields Formats."

If the "Events Sequence" (event sequential data) option is chosen, and the mouse is clicked on "OK," a screen is opened (see Figure 2) where, together with the bar menu (with the options "File," "Codes," "Subjects," and "Transcription," we can distinguish three areas of the screen.

Besides the standard functions of file management ("Save," "Save as," and "Exit"), the "File" option on the bar menu allows users to import (data from the Transcriptor program) and export (data from SDIS-GSEQ and The Observer). The "Codes" option makes it possible to introduce a new code (by selecting "New"), modify an existing one, or load an extant list of codes in another transcription. ${ }^{3}$ This structure also appears in the "Subjects" and "Transcription" options, although the latter has another option as well, "Observations" (see Appendix A).

If the "Conditions Sequences" (states) option is chosen in the first pull-down menu (see Figure 1), a window opens that contains the same options as in the "Events Sequence" (see Figure 2) but distributed in a different way (see Figure 3). All the windows ("Transcription," "Subjects," and "Codes") are grouped on the right-hand side

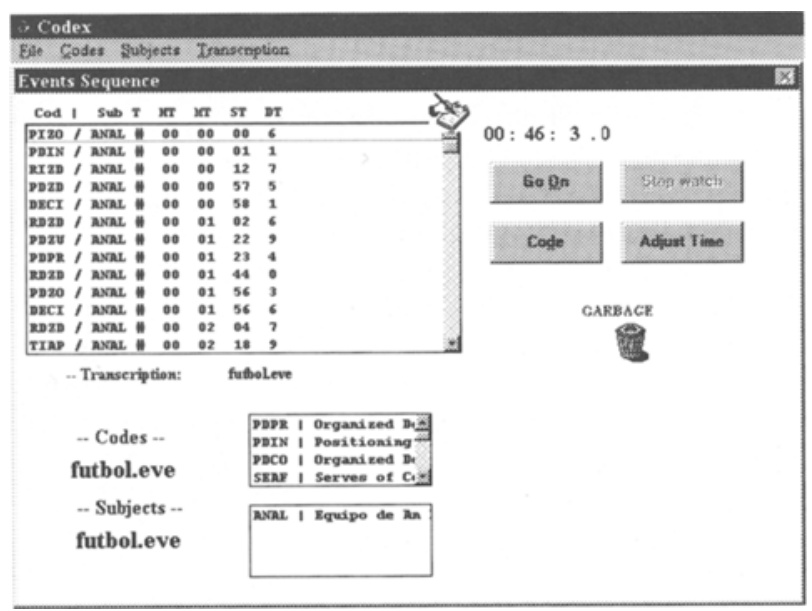

Figure 2. Screen for Events Sequence. 


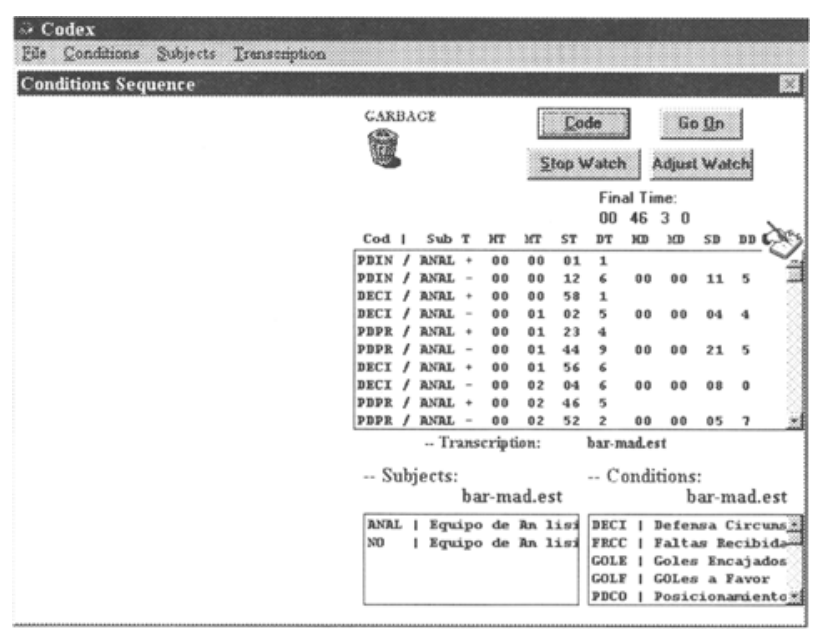

Figure 3. Screen for Conditions Sequence.

of the screen. On the left are the clocks activated by the different states as they appear. On the "Transcription" screen (see Figure 3), next to the indication of the subject to whom the state belongs, there is a "+" or a "--" symbol to indicate whether it is the beginning or end of the state, respectively, using the syntax indicated by Bakeman and Quera (1995).

The export option makes it possible to export data files to the SDIS-GSEQ (Bakeman \& Quera, 1995, 1996), The Observer 3.0 (Noldus, 1991), and Theme (Magnusson, 1988) programs (see Appendix B).

If the "Durability Events Sequence" (time event sequential data) option (see Figure 4) is chosen in the first pull-down menu (see Figure 1), the window that appears is similar to the one created in the previous option ("Conditions Sequence," state). The fundamental difference lies in the moment that behavioral flow is recorded, because, when recording occurs, it must be identified as an "Events Sequence" or a "Conditions Sequence" (state). On the transcription screen (see Figure 3), next to the indication of the subject to whom the state belongs, there is a "+" or a "-" symbol to indicate whether it is the beginning or the end of the state, respectively, using the syntax indicated by Bakeman and Quera (1995). The other options have the same function except for file interchange, which can be done only to SDIS GSEQ (Bakeman \& Quera, 1995, 1996) (see Appendix C).

For observations made with intervals ("Intervals" option; see Figure 1), the screen that pulls down is similar to the previous ones (see Figure 5). There is a new option referring to the type of interval. The interval type can only be set the first time. In this window, the length of the interval can be chosen in minutes or seconds, and the type of interval can be set: "Partial Interval Sampling," "Total Interval Sampling," or "Instantaneous Sampling." As in the previous case, data interchange can only be done to SDIS-GSEQ (Bakeman \& Quera, 1995, 1996) (see Appendix D).
If the decision is made for observation to take place through the use of "Fields Formats," when this option is chosen and the mouse is clicked on the "OK" button, a screen opens (see Figure 6). The distribution of the options on the screen is similar to those already discussed. The fundamental difference arises when the criteria and each of the codes belonging to these criteria are defined. When the "Criteria" option is chosen on the bar menu, and then the "New" option is chosen, a window is opened that defines the criterion in question. When the "OK" button is clicked, a new window opens where the different codes of this criterion are defined. These codes can be defined through the window that opens after defining each one or directly on each of the pull-down menus that appear on the left-hand side of the screen as the criteria are defined, maintaining the structure of the definition. On the "Criteria" menu, there is a new option that has not appeared before: "Change Position." This option makes it possible to change the order in which the criteria were defined. ${ }^{4}$ For purposes of exporting, data can be interchanged with the SDIS-GSEQ program (Bakeman \& Quera, 1995, 1996) and spread sheets or statistics packages. For export to SDIS-GSEQ, data are exported as interval data, which involves a conceptual change of the fields formats from their standard subject form to a time form (see Appendix E).

Accessing "In Situ Recording" can be done through the first screen in "Options" or by clicking the icon in the bottom left-hand corner of the screen. This opens a new screen that has the same data-type options as in "Taped Recording," except for the fields formats. When the options are chosen, screens open up that are similar to those described above. The basic difference is that, to record the behavioral flow (independently of the type of data being used), it is not necessary to stop the clock. Rather, recording takes place through a hot-key system, whereby the key of the first letter of the code and the number of the subject's order on the list are pressed. To find out which

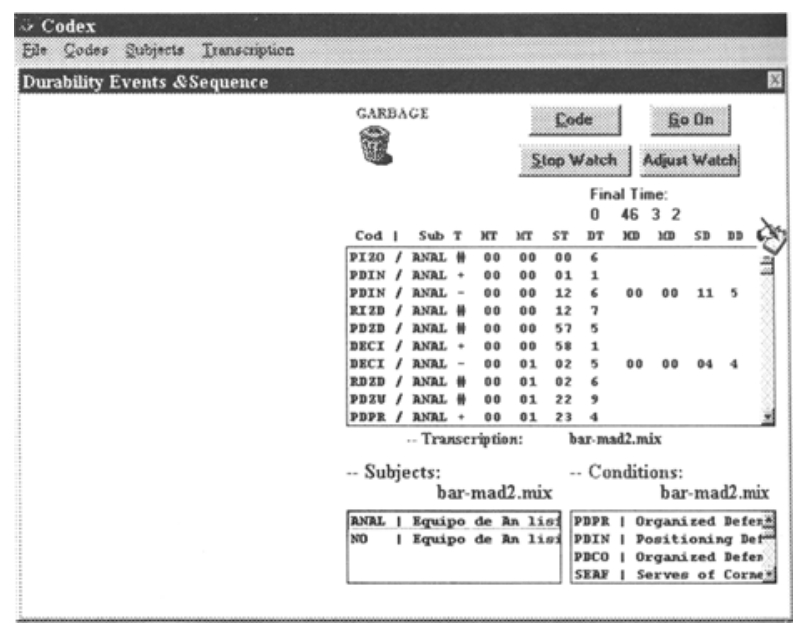

Figure 4. Screen for Durability Events Sequence. 


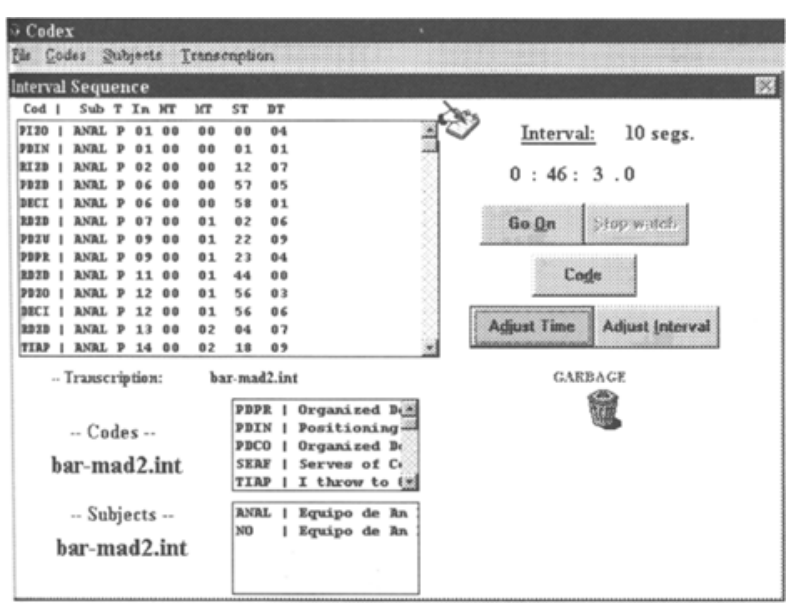

Figure 5. Screen for Intervals Sequence.

letter to choose, the " $\mathrm{T}$ " key is pressed, and a window opens with the corresponding codes and their respective letters.

\section{Conclusions}

This program provides an ideal solution to the problems arising from the use of observational methodology because of its ability to economize time. It is also flexible enough with regard to observation position (in situ recording and taped recording), the type of data used (events, states, time events, intervals, and field formats), and the type of behavior studied (motor and verbal).

All the data recorded and generated with this software can be quickly converted to other programs, such as SDIS-GSEQ (Bakeman \& Quera, 1995, 1996), The Observer 3.0 (Noldus, 1991), and Theme (Magnusson, 1993), and all types of spread sheets (Excel, Lotus, etc.), statistics packages (SPSS, BMPD, SYSTAT, etc.), word processors (Word Perfect, Word, etc.), and sound cards

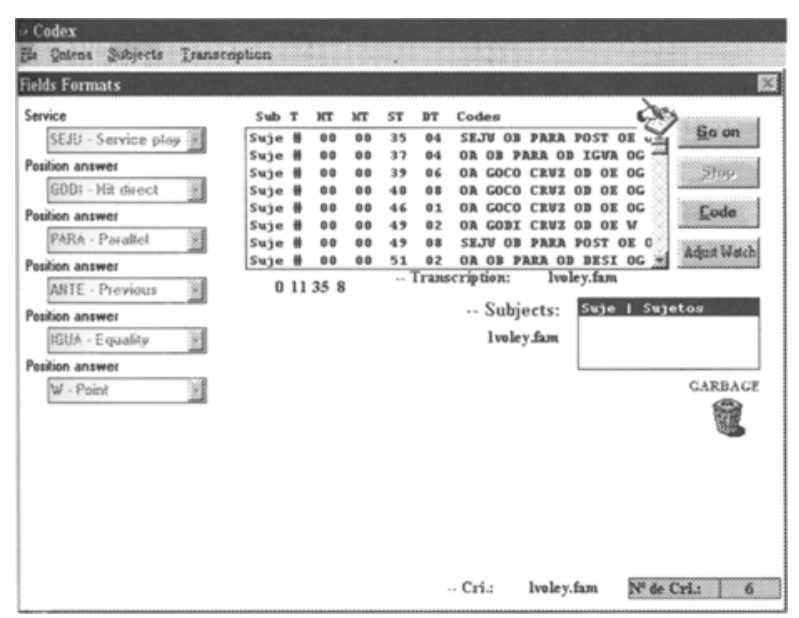

Figure 6. Screen for Fields Formats. that reproduce data emission (Sound Blaster). It can also import transcriptions from the Transcriptor program (Hernández Mendo, 1994; Hernández Mendo \& Ramos, 1996a, 1996b; Hernández Mendo et al., 1993; Peralbo et al., 1992; Ramos et al., 1994). Therefore, we consider it to be a useful tool in any context in which observational methodology is used, whether as a technique or a method, particularly in the sports field in both competition and research, because it is capable of being used in natural observation.

The program can be expanded along two lines: (1) in the implementation of indices for calculation of data quality (sequential concordance, Cohen's Kappa, etc.) and metric observation (mean and relative duration, relative frequency, conditioned relative frequency, etc.), and (2) in the implementation of a decision tree on the type of observational design to be used in terms of data type, number of subjects and sessions, category systems, and so on.

\section{REFERENCES}

Anguera, M. T. (1979, April). Observación de la conducta espacial. Paper presented at the VI Congreso Nacional de Psicología, Pamplona.

Bakeman, R., \& Quera, V. (1995). Analyzing interaction: Sequential analysis using SDIS and GSEQ. New York: Cambridge University Press.

Bakeman, R., \& Quera, V. (1996). Análisis de la interacción. Análisis Secuencial con SDIS GSEQ. Madrid: Ra-Ma.

HALL, E. T. (1963). A system for the notation of proxemic behavior. American Anthropologist, 65, 1003-1026.

HERnÁNDEZ MENDO, A. (1994). Construcción de herramientas informáticas para aplicación en Psicología del Deporte. Unpublished thesis, Universidad de Santiago de Compostela.

HERnÁndez MENDO, A. (1996). Observación y análisis de patrones de juego en deportes sociomotores [Doctoral thesis]. Santiago de Compostela: Servicio de Publicaciones e Intercambio Científico.

Hernández Mendo, A., \& Ramos, R. (1996a). Introducción a la informática aplicada a la psicología del deporte. Herramientas informáticas de uso en las ciencias del deporte. Madrid: Ra-Ma.

HeRnández Mendo, A., \& Ramos, R. (1996b). El uso de la informática aplicada a la evaluación y entrenamiento psicológico. In E. Pérez Cordoba \& J. C. Caracuel (Eds.), Psicologia del Deporte. Investigación y Aplicación (pp. 119-128). Málaga: Instituto Andaluz del Deporte.

Hernández Mendo, A., Ramos, R., Peralbo, M., \& Risso, A. (1993). Un programa para el análisis observacional: Transcriptor v1.1., Aplicación en psicologia del deporte. Revista de Entrenamiento Deportivo, 3, 18-25.

Hutr, S. J., \& Hutr, C. (1974). Direct observation and measurement of behavior. Springfield, IL: Charles C. Thomas.

IBáÑ̃z, E., Gorospe, G., \& HernándeZ MENDO, A. (1998, April-May). Una propuesta para evaluar las acciones de juego en voleibol. Paper presented at the $\mathrm{V}$ Congreso de Evaluación Psicológica, Benalmádena, Málaga.

Magnusson, M. S. (1988). Le temps et les patterns syntaxiques du comportement humain: Modele, méthode et le programme THĖME. In Revue des conditions de travail (pp. 284-314). Marseille: Octares.

Magnusson, M. S. (1993). THĖME User's manual. Reykjavik: University of Iceland.

Noldus, L. P. J. J. (1991). The Observer: A software system for collection and analysis of observational data. Behavior Research Methods, Instruments, \& Computers, 23, 415-429.

Peralbo, M., Risso, A., Ramos, R., \& Hernández Mendo, A. (1992). Programa informático para transcripción y análisis de datos observacionales. In C. M. Vide (Ed.), Actas del VII Congreso de Lenguajes Naturales y Lenguajes Formales (pp. 515-521). Barcelona: Universidad de Barcelona.

Ramos, R., Hernández Mendo, A., Peralbo, M., \& Risso, A. (1994). Análisis informático del proceso de observación. In C. Arce \& 
G. Seoane (Eds.), Actas III Simposium de Metodología de las Ciencias Sociales y Humanas (pp. 707-712). Santiago de Compostela: Universidad de Santiago de Compostela.

WEICK, K. E. (1968). Systematic observational methods. In G. Lindzey \& E. Aronson (Eds.), Handbook of social psychology (Vol. 2, pp. 357-451). Reading, MA: Addison-Wesley.

\section{NOTES}

1. The program can be downloaded, free of charge, in zip format from http:/www.sportquest.com/revista/soft/codex.zip
2. The authors of this software program are Maria Teresa Anguera Argilaga, Miguel Angel Bermúdez Rivera, Antonio Hernández Mendo, Manuel Peralbo Uzquiano, and Luz Zas Varela (inscription in the Registration of Intellectual Property, No. 1896, June 28, 1996).

3 . The program allows the user to access the lists of codes and subjects of different transcriptions, even if they come from another type of data. All the user has to do is change the file extension. If the "Load" option is used in "Transcription," all the codes and subjects necessary for transcription are loaded.

4. This is important for any subsequent conversions of "Fields Formats" into a category system.

\section{APPENDIX A \\ Event Sequential Data (Events Sequences)}

\section{Example:}

Let us consider a system of categories for the study of the motor action in football (Hernández Mendo, 1996).

PDPR: Organized Defensive positioning of Pressure

PDIN: Positioning Defensive Organized Intermission

PDCO: Organized Defensive positioning of Contention

DECI: Incidental defense

RDZU: Direct recovery in ultraoffensive area.

RDZO: Direct recovery in offensive area.

RDZD: Direct recovery in defensive area.

RIZU: Indirect recovery in ultraoffensive area.

RIZO: Indirect recovery in offensive area.

RIZD: Indirect recovery in defensive area.

PDZU: Direct loss in ultraoffensive area.

PDZO: Direct loss in offensive area.

PDZD: Direct loss in defensive area.

PIZU: Indirect loss in ultraoffensive area.

PIZO: Indirect loss in offensive area.

PIZD: Indirect loss in defensive area.

GOLF: Goals to Favor.

GOLE: Inserted goals.

TIAP: I throw to Goal.

RECH: Reject in Contrary Area.

SEAF: Serves of Corner to Favor.

SBCC: Serves of Band in Contrary Field.

FRCC: You lack Received in Contrary Field.

This transcription contains 188 registrations, here we have only included the beginning and the end. The observed match belongs to the Spanish football league of first division of the season 1995-1996 among the one Real Madrid vs. Barcelona. ANAL is the observed unit.

$\begin{array}{llllll}\text { PIZO / ANAL \# } & 00 & 00 & 00 & 6 \\ \text { PDIN / ANAL \# } & 00 & 00 & 01 & 1 \\ \text { RIZD / ANAL \# } & 00 & 00 & 12 & 7 \\ \text { PDZD / ANAL \# } & 00 & 00 & 57 & 5 \\ \text { DECI / ANAL \# } & 00 & 00 & 58 & 1 \\ \text { RDZD / ANAL \# } & 00 & 01 & 02 & 6 \\ \text { PDZU / ANAL \# } & 00 & 01 & 22 & 9 \\ \text { PDPR / ANAL \# } & 00 & 01 & 23 & 4 \\ \text { RDZD / ANAL \# } & 00 & 01 & 44 & 0\end{array}$




$\begin{array}{lllll}\text { DECI / ANAL \# } & 00 & 42 & 22 & 6 \\ \text { RIZD / ANAL \# } & 00 & 43 & 50 & 2 \\ \text { PDZO / ANAL \# } & 00 & 44 & 28 & 6 \\ \text { PDIN / ANAL \# } & 00 & 44 & 29 & 2 \\ \text { RDZO / ANAL \# } & 00 & 44 & 37 & 8 \\ \text { PDZO / ANAL \# } & 00 & 45 & 46 & 3 \\ \text { DECI / ANAL \# } & 00 & 45 & 47 & 5 \\ \text { RDZD / ANAL \# } & 00 & 45 & 53 & 0 \\ \text { PDZU / ANAL \# } & 00 & 46 & 02 & 3 \\ \text { PDPR / ANAL \# } & 00 & 46 & 02 & 8\end{array}$

APPENDIX B

State Sequential Data (Conditions Sequences)

Example:

Let us consider a system of categories that allows one to study the defensive positionings of the teams.

PDPR: Organized Defensive positioning of Pressure

PDIN: Positioning Defensive Organized Intermission

PDCO: Organized Defensive positioning of Contention

DECI: Incidental defense

This transcription contains 54 registrations (108 if we consider the beginnings "+" and the ends "-"). The observed match belongs to the Spanish football league of first division of the season 1995-1996 among the one Real Madrid vs. Barcelona. ANAL is the observed unit.

\begin{tabular}{|c|c|c|c|c|c|c|c|c|}
\hline PDIN / ANAL & +00 & 00 & 01 & 1 & & & & \\
\hline PDIN / ANAL & - 00 & 00 & 12 & 6 & 00 & 00 & 11 & 5 \\
\hline DECI / ANAL & +00 & 00 & 58 & 1 & & & & \\
\hline $\mathrm{DECI} / \mathrm{ANAL}$ & -00 & 01 & 02 & 5 & 00 & 00 & 04 & 4 \\
\hline PDPR / ANAL & +00 & 01 & 23 & 4 & & & & \\
\hline PDPR / ANAL & $-\quad 00$ & 01 & 44 & 9 & 00 & 00 & 21 & 5 \\
\hline $\mathrm{DECI} / \mathrm{ANAL}$ & +00 & 01 & 56 & 6 & & & & \\
\hline $\mathrm{DECI} / \mathrm{ANAL}$ & - $\quad 00$ & 02 & 04 & 6 & 00 & 00 & 08 & 0 \\
\hline PDPR / ANAL & +00 & 02 & 46 & 5 & & & & \\
\hline PDPR / ANAL & -00 & 02 & 52 & 2 & 00 & 00 & 05 & 7 \\
\hline$\cdot$ & & & & & & & & \\
\hline · & & & & & & & & \\
\hline$\cdot$ & & & & & & & & \\
\hline DECI / ANAL & +00 & 41 & 00 & 6 & & & & \\
\hline $\mathrm{DECI} / \mathrm{ANAL}$ & -00 & 41 & 06 & 4 & 00 & 00 & 05 & 8 \\
\hline DECI / ANAL & +00 & 42 & 22 & 6 & & & & \\
\hline $\mathrm{DECI} / \mathrm{ANAL}$ & -00 & 43 & 50 & 1 & 00 & 01 & 27 & 5 \\
\hline PDIN / ANAL & +00 & 44 & 29 & 2 & & & & \\
\hline PDIN / ANAL & -00 & 44 & 37 & 7 & 00 & 00 & 08 & 5 \\
\hline $\mathrm{DECI} / \mathrm{ANAL}$ & +00 & 45 & 47 & 5 & & & & \\
\hline DECI / ANAL & -00 & 45 & 53 & 9 & 00 & 00 & 06 & 4 \\
\hline PDPR / ANAL & +00 & 46 & 02 & 8 & & & & \\
\hline PDPR / ANAL & - $\quad 00$ & 46 & 03 & 9 & 00 & 00 & 01 & 1 \\
\hline
\end{tabular}


APPENDIX C
Time Events Sequential Data (Durability Events Sequences)

Example:

Let us consider a system of categories for the study of the motor action in football (Hernández Mendo, 1996).

PDPR: Organized Defensive positioning of Pressure

PDIN: Positioning Defensive Organized Intermission

PDCO: Organized Defensive positioning of Contention

DECI: Incidental defense

RDZU: Direct recovery in ultraoffensive area.

RDZO: Direct recovery in offensive area.

RDZD: Direct recovery in defensive area.

RIZU: Indirect recovery in ultraoffensive area.

RIZO: Indirect recovery in offensive area.

RIZD: Indirect recovery in defensive area.

PDZU: Direct loss in ultraoffensive area.

PDZO: Direct loss in offensive area.

PDZD: Direct loss in defensive area.

PIZU: Indirect loss in ultraoffensive area.

PIZO: Indirect loss in offensive area.

PIZD: Indirect loss in defensive area.

GOLF: Goals to Favor.

GOLE: Inserted goals.

TIAP: I throw to Goal.

RECH: Reject in Contrary Area.

SEAF: Serves of Corner to Favor.

SBCC: Serves of Band in Contrary Field.

FRCC: You lack Received in Contrary Field.

This transcription contains 486 registrations (included the beginnings "+" and the ends "-" of the states), here we have only included the beginning and the end. The observed match belongs to the Spanish league of first division of the season 1995-1996 among the one Real Madrid vs. Barcelona. ANAL is the observed unit.

$\begin{array}{llllllllll}\text { PIZO / ANAL \# } & 00 & 00 & 00 & 6 & & & & \\ \text { PDIN / ANAL + } & 00 & 00 & 01 & 1 & & & & \\ \text { PDIN / ANAL - } & 00 & 00 & 12 & 6 & 00 & 00 & 11 & 5 \\ \text { RIZD / ANAL \# } & 00 & 00 & 12 & 7 & & & & \\ \text { PDZD / ANAL \# } & 00 & 00 & 57 & 5 & & & & \\ \text { DECI / ANAL + } & 00 & 00 & 58 & 1 & & & & \\ \text { DECI / ANAL - } & 00 & 01 & 02 & 5 & 00 & 00 & 04 & 4 \\ \text { RDZD / ANAL \# } & 00 & 01 & 02 & 6 & & & & \\ \text { PDZU / ANAL \# } & 00 & 01 & 22 & 9 & & & & \\ \text { PDPR / ANAL + } & 00 & 01 & 23 & 4 & & & & \\ \text { PDPR / ANAL - } & 00 & 01 & 44 & 9 & 00 & 00 & 21 & 5 \\ \text {. } & & & & & & & & \\ \text { - } & & & & & & & & \\ \text { PDIN / ANAL + } & 00 & 44 & 29 & 2 & & & & \\ \text { PDIN / ANAL - } & 00 & 44 & 37 & 7 & 00 & 00 & 08 & 5 \\ \text { RDZO / ANAL \# } & 00 & 44 & 37 & 8 & & & & \end{array}$




\section{APPENDIX C (Continued)}

\begin{tabular}{llllllllll}
\hline PDZO / ANAL \# & 00 & 45 & 46 & 3 & & & & \\
DECI / ANAL + & 00 & 45 & 47 & 5 & & & & & \\
DECI / ANAL - & 00 & 45 & 53 & 9 & 00 & 00 & 06 & 4 & \\
RDZD / ANAL \# & 00 & 45 & 53 & 0 & & & & & \\
PDZU / ANAL \# & 00 & 46 & 02 & 3 & & & & & \\
PDPR / ANAL + & 00 & 46 & 02 & 8 & & & & & \\
PDPR / ANAL - & 00 & 46 & 03 & 0 & 00 & 00 & 00 & 2 \\
\hline
\end{tabular}

\section{APPENDIX D \\ Interval Sequential Data (Intervals Sequences)}

\section{Example:}

Let us consider a system of categories for the study of the motor action in football

(Hernández Mendo, 1996).

PDPR: Organized Defensive positioning of Pressure

PDIN: Positioning Defensive Organized Intermission

PDCO: Organized Defensive positioning of Contention

DECI: Incidental defense

RDZU: Direct recovery in ultraoffensive area.

RDZO: Direct recovery in offensive area.

RDZD: Direct recovery in defensive area.

RIZU: Indirect recovery in ultraoffensive area.

RIZO: Indirect recovery in offensive area.

RIZD: Indirect recovery in defensive area.

PDZU: Direct loss in ultraoffensive area.

PDZO: Direct loss in offensive area.

PDZD: Direct loss in defensive area.

PIZU: Indirect loss in ultraoffensive area.

PIZO: Indirect loss in offensive area.

PIZD: Indirect loss in defensive area.

GOLF: Goals to Favor.

GOLE: Inserted goals.

TIAP: I throw to Goal.

RECH: Reject in Contrary Area.

SEAF: Serves of Corner to Favor.

SBCC: Serves of Band in Contrary Field.

FRCC: You lack Received in Contrary Field.

This transcription contains 189 registrations, here we have only included the beginning and the end. The observed match belongs to the Spanish football league of first division of the season 1995-1996 among the one Real Madrid vs. Barcelona. ANAL is the observed unit.

$\begin{array}{lllllll}\text { PIZO | ANAL } & \text { P } & 01 & 00 & 00 & 00 & 04 \\ \text { PDIN } \mid \text { ANAL } & \text { P } & 01 & 00 & 00 & 01 & 01 \\ \text { RIZD | ANAL } & \text { P } & 02 & 00 & 00 & 12 & 07 \\ \text { PDZD | ANAL } & \text { P } & 06 & 00 & 00 & 57 & 05 \\ \text { DECI | ANAL } & \text { P } & 06 & 00 & 00 & 58 & 01 \\ \text { RDZD | ANAL } & \text { P } & 07 & 00 & 01 & 02 & 06 \\ \text { PDZU | ANAL } & \text { P } & 09 & 00 & 01 & 22 & 09 \\ \text { PDPR | ANAL } & \text { P } & 09 & 00 & 01 & 23 & 04\end{array}$


APPENDIX D (Continued)

\begin{tabular}{lllllll}
\hline RDZD | ANAL P & 11 & 00 & 01 & 44 & 00 \\
PDZO | ANAL & $P$ & 12 & 00 & 01 & 56 & 03 \\
& & & & & & \\
& & & & & & \\
DECI | ANAL & P255 & 00 & 42 & 22 & 06 \\
RIZD | ANAL & P263 & 00 & 43 & 50 & 02 \\
PDZO | ANAL & P267 & 00 & 44 & 28 & 06 \\
PDIN | ANAL & P267 & 00 & 44 & 29 & 02 \\
RDZO | ANAL & P268 & 00 & 44 & 37 & 08 \\
PDZO | ANAL & P275 & 00 & 45 & 46 & 03 \\
DECI | ANAL & P275 & 00 & 45 & 47 & 05 \\
RDZD | ANAL & P276 & 00 & 45 & 53 & 00 \\
PDZU | ANAL & P277 & 00 & 46 & 02 & 03 \\
PDPR | ANAL & P277 & 00 & 46 & 02 & 08
\end{tabular}

APPENDIX E

Fields Formats

Let us consider a system of categories for the study of the motor action in volleyball (Ibañez, Gorospe, \& Hernández Mendo, 1998).

1. Service

SEJU:Service player

SEAD:opposing Service

OA:Group empty Service

2. Hit

GODI: Hit direct

GOCO: Hit communication

OB:empty Group Hits

3. Trajectory

FOR:Parallel

CRUZ:Crusade

OC:Group empty Trajectory

4. Position answer

ANTE:Previous

POST:Later

OD:Group empty Position answer

5. Positioning team

IGUA:Equality

DESI:Inequality

OE:empty Group Positioning team

6. Rupture

W:Point

F:Failure

OG:Group empty Rupture

This transcription contains 193 registrations, here we have only included the beginning and the end. The observed match belongs to the Spanish volleyball league of first division of the season 1995-1996 among the one Iversur-Málaga vs. Granada-university. "Suje" is the observed unit.

Suje \# $00 \quad 00 \quad 35 \quad 04 \quad$ SEJU OB PARA POST OE OG

Suje \# $00 \quad 000037 \quad 04 \quad$ OA OB PARA OD IGUA OG

Suje \# $00 \quad 00 \quad 39 \quad 06 \quad$ OA GOCO CRUZ OD OE OG

Suje \# $00 \begin{array}{lllll}00 & 40 & 08 & \text { OA GOCO CRUZ OD OE OG }\end{array}$

Suje \# $00 \quad 00 \quad 46 \quad 01 \quad$ OA GOCO CRUZ OD OE OG 


\section{APPENDIX E (Continued)}

Suje \# $00 \begin{array}{lllll}00 & 49 & 02 & \text { OA GODI CRUZ OD OE W }\end{array}$

Suje \# 0000004908 SEJU OB PARA POST OE OG

Suje \# $00 \begin{array}{lllll}00 & 51 & 02 & \text { OA OB PARA OD DESI OG }\end{array}$

Suje \# $00 \begin{array}{llllll}00 & 51 & 02 & \text { OA GOCO CRUZ OD OE OG }\end{array}$

Suje \# $00 \begin{array}{lllll}00 & 52 & 02 & \text { OA GOCO CRUZ OD OE OG }\end{array}$

\begin{tabular}{llllll} 
Suje \# & 00 & 11 & 04 & 04 & OA GODI PARA OD OE F \\
Suje \# & 00 & 11 & 09 & 06 & SEAD OB PARA OD DESI OG \\
Suje \# & 00 & 11 & 13 & 00 & OA GOCO PARA OD OE OG \\
Suje \# & 00 & 11 & 14 & 00 & OA GOCO PARA OD OE OG \\
Suje \# & 00 & 11 & 18 & 06 & OA GODI PARA ANTE OE OG \\
Suje \# & 00 & 11 & 19 & 05 & OA OB PARA OD DESI F \\
Suje \# & 00 & 11 & 27 & 04 & SEJU OB PARA POST OE OG \\
Suje \# & 00 & 11 & 28 & 02 & OA OB CRUZ OD DESI OG \\
Suje \# & 00 & 11 & 29 & 00 & OA GODI PARA ANTE OE OG \\
Suje \# & 00 & 11 & 32 & 08 & OA OB PARA OD IGUA OG \\
Suje \# & 00 & 11 & 35 & 08 & OA GODI CRUZ OD OE W \\
\hline
\end{tabular}

(Manuscript received May 20, 1999;

revision accepted for publication March 14, 2000.) 